\title{
IKZF1 Gene Mutation
}

National Cancer Institute

\section{Source}

National Cancer Institute. IKZF1 Gene Mutation. NCI Thesaurus. Code C79425.

A change in the nucleotide sequence of the IKZF1 gene. 